16 a 18 de outubro de 2019 - Campinas | Brasil

\title{
Simulation of water pollutants dispersion in reservoir of Salto Grande.
}

\section{Larissa Macul Moreno*, João Frederico C. A. Meyer}

\section{Abstract}

Using a diffusion-advection-reaction partial differential equation, we try to computationally simulate the dispersion effect of pollutants in aquatic environments. This study will focus on the current crisis in Americana's reservoir, Salto Grande, provoked by improper disposal of industrial and domestic waste.

\section{Key words:}

Biomathematics, Partial Differential Equations, Numerical Analysis

\section{Introduction}

In the 50's, the dam and reservoir of Salto Grande were built for hydroelectric energy generation, boosting the Atibaia river's bank industrialization and urbanization. The consequences of years in environmental degradation can be seen in the state of emergency of the city Americana, that, according to the story from $\mathrm{G} 1^{4}$, was taken over by water hyacinth nourished by urban and domestic pollution disposal which severely endangers the biota in the reservoir waters.

With this motivation, we formulated a mathematical model for the dispersion of pollutants through a diffusion problem and the associated numerical solution.

\section{Results and Discussion}

To simulate the propagation of the pollution concentration dynamic behavior we chose the classic diffusionadvection-reaction partial differential equation, from Okubo $^{5}$ and Edelstein-Keshet ${ }^{3}$. We are interested in calculating the approximate numerical solution of the differential equation to obtain a description of the temporal variation in a smooth bidimensional domain similar to the reservoir of Salto Grande.

$$
\begin{array}{r}
\frac{\partial c}{\partial t}(x, y, t)-\alpha \Delta c(x, y, t)+\nabla c(x, y, t) \cdot V+\mu c(x, y, t)=f, \\
(x, y) \in \Omega \subset \mathbb{R}^{2} \text { e } t \in J=(0, T]
\end{array}
$$

\section{Equation 1.}

where $c=c(x, y, t)$ is the pollutant concentration, $\alpha$ is the diffusion coefficient, $V$ is vector representation of the dominant advective wind, $\mu$ is the decay or absorption coefficient, $f$ represents the sources of pollution, $\Omega$ is the spatial domain, $J$ is the temporal domain and $T$ is the final time of simulation.

For the numerical treatment, we chose the Finite Differential Method for spatial approximation and the Crank-Nicolson Method for temporal approximation, from Burden, Faires ${ }^{1}$.

Both numerical and visual qualitative results were executed with the software Matlab. The results simulate the diffusive effect through time in a spatial domain, from Zamora $^{6}$, similar to the reservoir of Salto Grande, as can be seen in Figure 1.

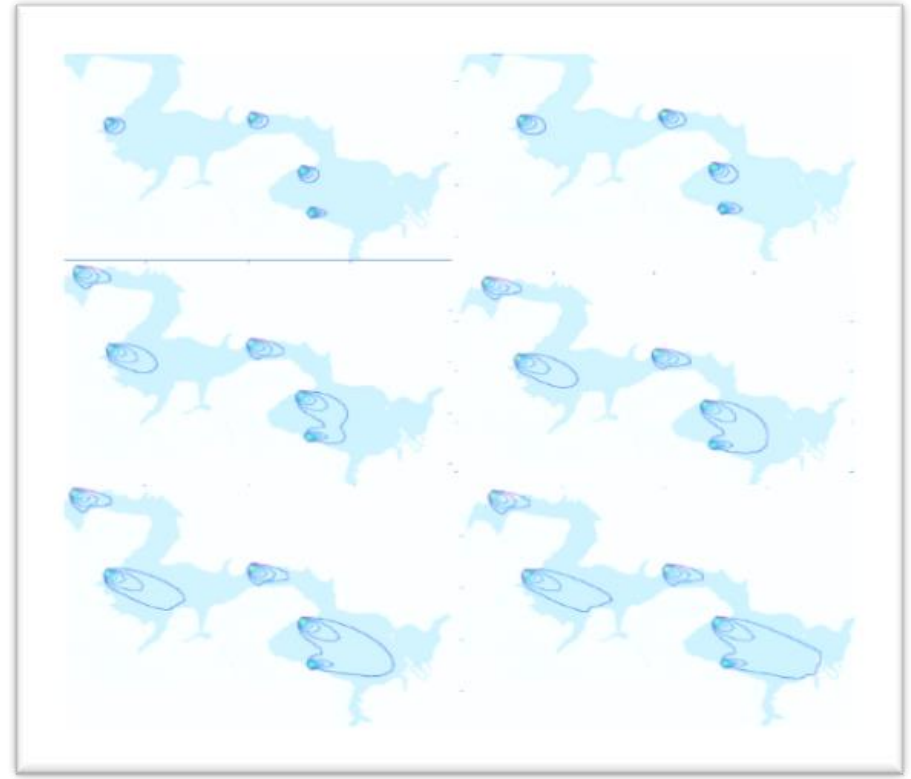

Image 1. Simulation of pollution waves diffusion in reservoir of Salto Grande.

\section{Conclusions}

This work represents an initial effort to simulate different. scenarios of pollutant diffusion in aquatic environments using numerical approximation methods. We hope the developed computational resources may contribute in the creation and establishment of public politics for the recuperation of reservoir of Salto Grande and it's waters.

\section{Acknowledgement}

We thank UNICAMP and IMECC for the structural support.

${ }^{1}$ Burden R. L.; Faires, J. D. Numerical Analysis. 6. ed. Boston: Brooks/Cole, 1997.

${ }^{2}$ G. L. Diniz, J. F. C. A. Meyer. Estudo e modelagem da dispersão de poluentes em sistemas estuarinos, Biomatemática, v. 14, n. 10, p. 103-118, 2004.

${ }^{3}$ Edelstein-Keshet, L. Mathematicals Models in Biology. 1 ed. N. York: Random-House, 1988.

${ }^{4} \mathrm{G} 1$. Salto-Grande: 11 cidades da região descumprem medidas de preservação da represa, diz MP. 2019. www.g1.globo.com/sp/campinas-regiao. Acesso em: 15 mar. 2019

${ }^{5}$ Okubo, A. Diffusion and Ecological Problems: Mathematical Models. Berlin: Springer, 1980

${ }^{6}$ Zamora, J. L. C. Dinâmicas Populacionais na Presença de Poluentes ..., Dissertação (Doutorado em Matemática Aplicada) - Unicamp, Campinas. 2016. 